\title{
GRANULOMA EOSINÓFILO DE LOCALIZACIÓN CRANEAL: REPORTE DE UN CASO Y REVISIÓN BIBLIOGRÁFICA
}

\author{
EOSINOPHILIC GRANULOMA OF CRANIAL LOCATION: REPORT OF A CASE AND BIBLIOGRAPHIC \\ REVIEW
}

\section{GRANULOMA EOSINOFÍLICO DE LOCALIZAÇÃO CRANIANA: RELATO DE UM CASO E REVISÃO BIBLIOGRÁFICA}

\author{
Juan Ramon y Cajal Calvo ${ }^{1}$, Enrique Alvarez Arranz², Marta Zamora Lozano³.
}

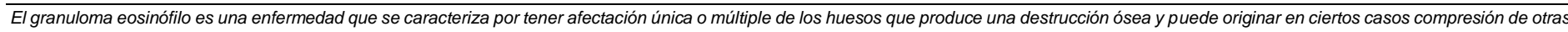
estructuras cercanas. Es un trastorno que se da en la mayoría de los casos en pacientes jóvenes menores de 30 años y que tiene un buen pronóstico si se realiza un diagnóstico precoz y certero

\section{Conceptos clave: \\ Resumen:}

¿Qué se sabe sobre el tema? El granuloma eosinófilo es la variante más benigna de la Histiocitosis X. Se trata de una lesión lítica del hueso originada por una anormal proliferación de histiocitosis, con claro predominio en pacientes pediátricos y adultos jóvenes.

¿Qué aporta este trabajo? Se presenta el caso de una paciente con granuloma eosinófilo monostótico con ausencia de metástasis y con clínica característica. Las imágenes tanto ecográficas como de la tomografía computarizada muestran un patrón característico de esta patología. Este artículo aporta conocimientos centrados en los hallazgos radiológicos incluyendo imágenes anatomopatológicas de la lesión extirpada en su totalidad.

1- Médico Servicio de radiodiagnóstico del Hospital Clinico Universitario Lozano Blesa. Zaragoza. España. Graduado en Medicina por la Universidad de Zaragoza. Máster de Iniciación a la investigación en medicina. Universidad de Zaragoza.

E-mail de contacto: jramonycajalı@gmail.com

2- Facultativo Especialista de área. Servicio de Intervencionismo. Hospital Clinico Universitario Lozano Blesa. Licenciado en Medicina. Universidad del País Vasco. Escuela del doctorado. Universidad de Medicina de Zaragoza. E-mail: kikealvarez86@gmail.com

3- Médico Servicio de traumatología de cirugía ortopédica del Hospital Clinico Universitario Lozano Blesa. Zaragoza. España Graduado en Medicina por la Universidad de Zaragoza

Máster de Iniciación a la investigación en medicina. Universidad de Zaragoza. E-mail: mzamoralozano@gmail.com

Recibido: 2020-12-03 Aceptado: 2021-01-15

DOI: http://dx.doi.org/10.31053/1853.0605.v78.n1.30451
Introducción: El granuloma eosinófilo es una enfermedad benigna poco usual que suele afectar a la población pediátrica y adultos jóvenes. Es la afección más benigna de las enfermedades tradicionalmente conocidas como histiocitosis $X$ que en la actualidad reciben la denominación de histiocitosis de células de Langerhans.

Caso Clínico: Paciente pediátrico con prominencia dolorosa en región temporal. Las pruebas de imagen realizadas ponen de manifiesto la existencia de una lesión osteolítica con patrón de agresividad compatible con granuloma eosinófilo. El paciente es intervenido mediante cirugía con diagnóstico histológico definitivo concluyente de granuloma eosinófilo.

Discusión: El granuloma eosinófilo puede afectar a uno o múltiples huesos, de los cuáles los más frecuentes son los huesos craneales, epífisis de huesos largos y costillas, precisando estrategias de diagnóstico y tratamiento individualizadas para un manejo y resultado óptimo, siendo el tratamiento quirúrgico de primera elección.

Conclusión: El granuloma eosinófilo es un cuadro benigno infrecuente que requiere de una correcta anamnesis y exploración clínica del paciente, así como la demostración de las imágenes radiológicas características, permitiendo llegar a un diagnóstico de presunción generalmente certero que en la mayoría de ocasiones se puede considerar definitivo.

Palabras claves: histiocitosis de células de langerhans; pediatría; hueso temporal

\section{Abstract:}

Introduction: Eosinophilic granuloma is an unusual benign disease that usually affects the pediatric population and young adults. It is the most benign of the diseases traditionally known as histiocytosis $\mathrm{X}$ that are now called Langerhans cell histiocytosis.

Clinical Case: Pediatric patient with a painful prominence in the temporal region. The imaging tests carried out reveal the existence of an osteolytic lesion with an aggressive pattern compatible with eosinophilic granuloma. The patient underwent surgery with a conclusive definitive histological diagnosis of eosinophilic granuloma.

Discussion: Eosinophilic granuloma can affect one or multiple bones, of which the most frequent are the cranial bones, epiphyses of long bones and ribs, requiring individualized diagnosis and treatment strategies for optimal management and results, with surgical treatment of First choice.

Conclusion: Eosinophilic granuloma is an infrequent benign condition that requires a correct anamnesis and clinical examination of the patient, as well as the demonstration of the characteristic radiological images, allowing a generally accurate presumptive diagnosis to be reached that in most cases can be considered definitive.

Keywords: histiocytosis, langerhans-cell; pediatrics; temporal bone

\section{Resumo}

Introdução: O granuloma eosinofílico é uma doença benigna incomum que geralmente afeta a população pediátrica e adultos jovens. É a mais benigna das doenças tradicionalmente conhecidas como histiocitose $\mathrm{X}$, que agora são denominadas histiocitose de células de Langerhans.

Caso Clínico: Paciente pediátrico com nódulo doloroso em região temporal. Os exames de imagem realizados revelam a existência de lesão osteolítica de padrão agressivo compatível com granuloma eosinofílico. O paciente foi submetido a cirurgia com diagnóstico histológico definitivo conclusivo de granuloma eosinofílico.

Discussão: O granuloma eosinofílico pode acometer um ou vários ossos, sendo os mais frequentes os ossos cranianos, epífises de ossos longos e costelas, exigindo diagnóstico individualizado e estratégias de tratamento para manejo e resultados ideais, com tratamento cirúrgico de Primeira escolha.

Conclusão: O granuloma eosinofílico é uma condição benigna infrequente que requer a correta anamnese e exame clínico do paciente, bem como a demonstração das imagens radiológicas características, permitindo chegar a um diagnóstico presuntivo geralmente acurado que na maioria dos casos pode ser considerado definitivo.

Palavras chave: histiocitose de células de langerhans; pediatria; osso temporal 


\section{Introducción}

El granuloma eosinófilo (GE) es una enfermedad inusual que afecta predominantemente a pacientes pediátricos y adultos jóvenes. EI GE es la afección más benigna del espectro de entidades clínicas que tradicionalmente se denominaban histiocitosis X, y que en la actualidad reciben el nombre de histiocitosis de células de Langerhans.

Presentamos el caso clínico de una paciente pediátrica con la aparición de una prominencia dolorosa en la región temporal que gracias a los hallazgos en las pruebas de imagen fue correctamente diagnosticada y tratada mediante cirugía de un granuloma eosinófilo, con una satisfactoria mejoría y evolución clínica posterior.

\section{Caso Clínico}

Se presenta una paciente de 11 años de edad, que acude al servicio de urgencias de nuestro centro hospitalario por dolor en la región frontotemporal derecha de 1 mes de evolución sin antecedente traumático asociado.

La paciente no refiere ninguna otra clínica asociada y no presentaba antecedentes personales ni familiares de interés.

A la exploración física, se objetiva una tumefacción en la región temporal derecha de aproximadamente $2 \times 2 \mathrm{~cm}$ sin eritema, rubor ni calor asociado, muy doloroso a la palpación. La exploración neurológica pone de manifiesto un Glasgow 15/15 y no muestra alteraciones en los pares craneales. El resto de exploración física y valores analíticos no demuestran ninguna alteración significativa.

Se decide realizar pruebas complementarias de imagen, comenzando por una radiografía de cráneo que evidencia una lesión lítica de bordes mal definidos, no escleróticos en localización temporal derecha anterior (figura 1). Ante la existencia de la lesión, se decide ampliar el estudio mediante ecografía y tomografía axial computarizada (TAC). Los estudios radiológicos ponen de manifiesto la presencia de una lesión craneal osteolítica con patrón geográfico de tipo I C, con alta agresividad que produce una destrucción de la cortical anterior del hueso temporal derecho y parece tener una invasión intracraneal (figuras 2 y 3 ).

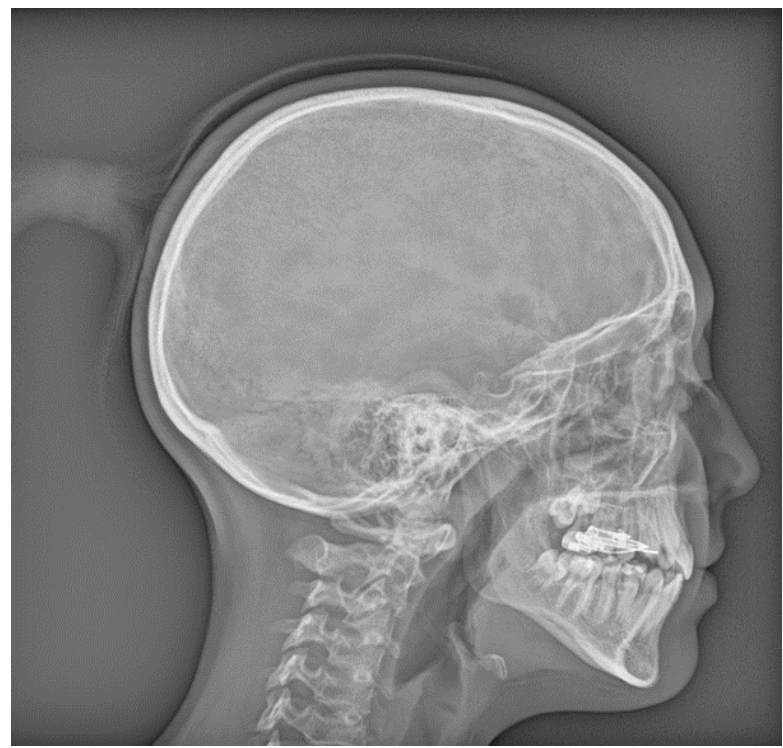

Figura 1: Radiografía craneal proyección lateral: se visualiza una lesión lítica de bordes mal definidos, no escleróticos en localización temporal derecha anterior.

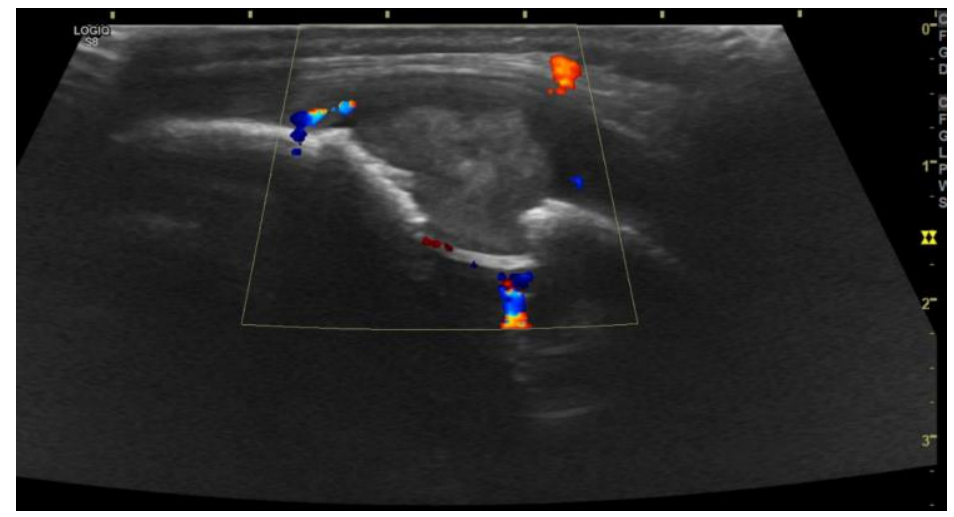

Figura 2: Ecografía de partes blandas: imagen hipoecogénica heterogénea de $2 \times 2 \mathrm{~cm}$, con captación Doppler en su interior, que invade y produce destrucción de la cortical craneal subyacente.

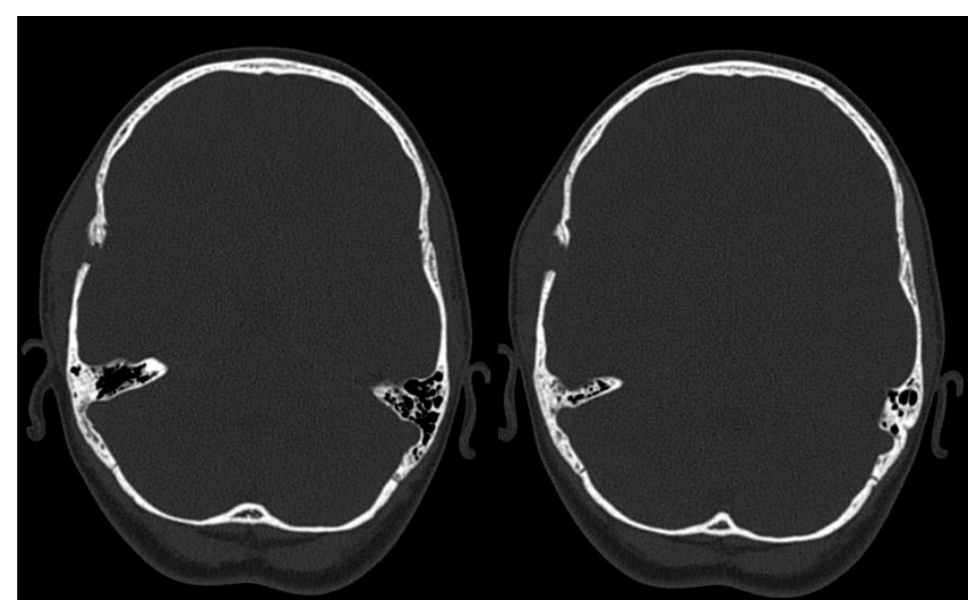

Figura 3: TC sin CIV cortes axiales: existencia de una lesión craneal osteolítica con patrón geográfico tipo I C, con alta agresividad, localizada en la porción más anterior del hueso temporal derecho.

Los hallazgos radiológicos y el rango de edad de la paciente son compatibles con Granuloma eosinófilo como primera opción diagnóstica, si bien no se puede descartar que se trate de una lesión neoplásica primaria o metastásica, motivo por el que se completa la filiación de la misma con una gammagrafía ósea de cuerpo completo en fase de captación ósea (figura 4). Los resultados refieren un aumento focal de la vascularización con hipercaptación del trazador en fase ósea de escasa cantidad, mostrando en fase tardía una captación en anillo con centro hipocaptante acorde al comportamiento lítico de la lesión. No se observan otras alteraciones significativas de la captación en otras localizaciones a distancia. 


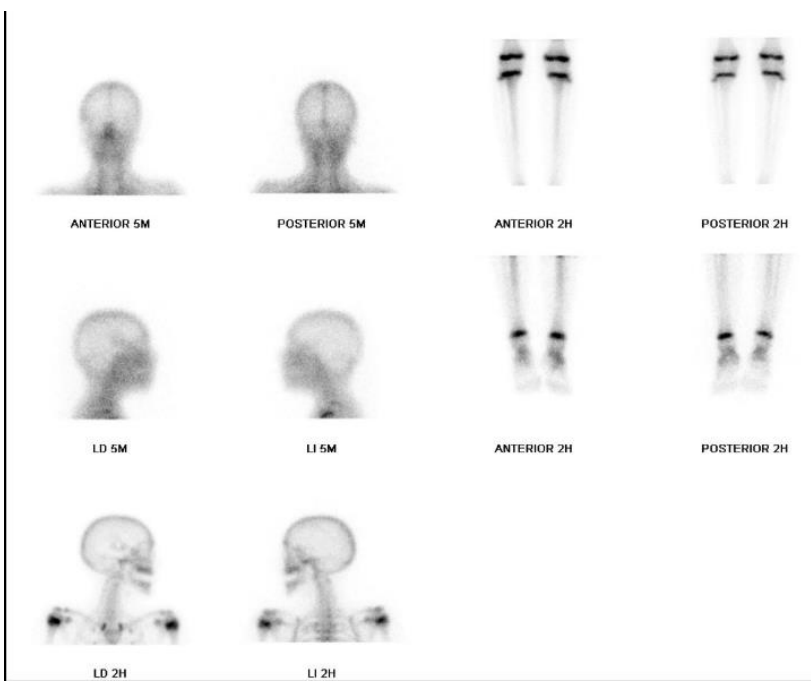

Figura 4: Gammagrafía ósea proyecciones AP y laterales. La lesión a estudio en región temporal derecha muestra aumento focal de la vascularización, con hipercaptación del trazador en fase ósea, de escasa intensidad.

Se decide llevar a cabo una intervención quirúrgica por parte del servicio de neurocirugía de nuestro centro, realizándose una incisión temporal derecha y encontrándose una lesión lítica granulomatosa que es resecada por completo. Los resultados anatomopatológicos intraoperatorios y definitivos de la pieza extirpada demuestran signos histopatológicos compatibles con el diagnóstico de granuloma eosinófilo (figura 5).

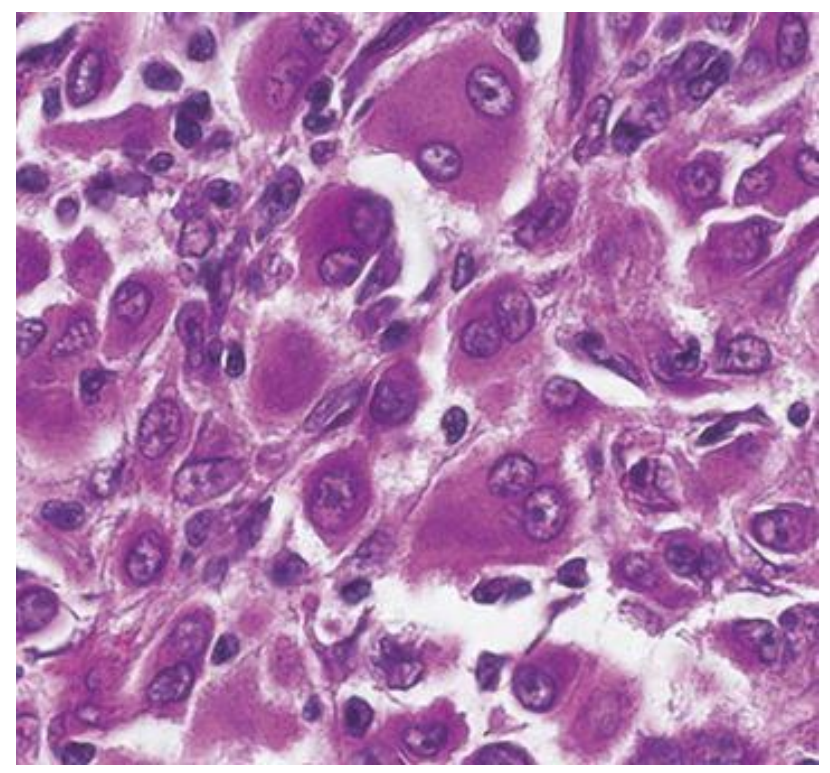

Figura 5: Anatomía patológica: Eosinófilos con presencia de proliferación de células de Langerhans.

La evolución postoperatoria fue favorable siendo dada de alta hospitalaria a los pocos días de la intervención debido a la mejoría y estabilidad clínica.

\section{Discusión}

El granuloma eosinófilo (GE), también conocido como Histiocitosis de células de Langerhans (HCL) fue descrito por primera vez en el año 1940 por Lichtenstein y Jaffe. ${ }^{1}$

Se trata de una patología poco frecuente, de carácter benigno, similar a un tumor, caracterizado por la proliferación clonal de células mononucleares presentadoras de antígeno de origen dendrítico conocidas como células de Langerhans. El granuloma eosinófilo representa el $70 \%$ del número total de casos de HCL además de ser el tipo de presentación más localizado y benigno. ${ }^{2}$

Epidemiológicamente presenta una incidencia anual de 3-4 casos por millón con un claro predominio en pacientes pediátricos y adultos jóvenes entre la primera y la tercera década de la vida. ${ }^{3}$

La presentación clínica típica es la manifestación de dolor con aumento de volumen en la zona de la lesión y los tejidos adyacentes.

EI GE óseo puede afectar a uno o múltiples huesos, siendo los más frecuentes los huesos craneales, epífisis de huesos largos, costillas, vértebras y mandíbula. ${ }^{2}$ La presentación monostótica es más frecuente que la poliostótica, si bien esta última comprende entorno al 20-30 \% de los casos. ${ }^{4}$

Los hallazgos radiológicos son fundamentalmente los de una lesión radiolúcida, redondeada y de bordes bien definidos. Mediante TAC se observan con mayor claridad las características osteolíticas de la lesión y su posible invasión extraósea hacia los tejidos adyacentes. La experiencia con la gammagrafía ósea y con la tomografía por emisión de positrones (PET) en la evaluación del GE es limitada y sus aplicaciones están todavía en periodos de investigación. Diferentes estudios parecen indicar que es muy sensible para la detección de la lesión y muy específicos en la fase de actividad.

En el cráneo la lesión se presenta como una tumoración que puede presentar un crecimiento intracraneal y comprimir la masa encefálica. Debemos sospechar de GE en el hueso temporal en los casos de pacientes con otitis medias resistentes al tratamiento antibiótico. Otra forma de afectación craneal, en este caso del hueso mandibular o maxilar descrita es la de la debilidad de las piezas dentarias adyacentes a la lesión. ${ }^{5}$

Los parámetros analíticos en la mayoría de las ocasiones presentan valores dentro de la normalidad, aunque pueden encontrarse leucocitosis, eosinofilia y aumento de la velocidad de sedimentación globular (VSG).

El diagnóstico definitivo requiere de una confirmación anatomopatológica, debido a que tanto las manifestaciones clínicas como las características radiológicas se pueden superponer con diversos procesos patológicos, incluyendo la osteomielitis, osteocondritis y procesos neoplásicos como plasmocitomas, meningiomas, hemangiopericitoma, mieloma o metástasis. ${ }^{6}$

Histológicamente la propiedad esencial es la proliferación de células de Langerhans y su infiltración en los téjidos. Las células de Langerhans tienen en común una serie de marcadores inmunohistoquímicos como son el S-100, CD1a, CD52, CD40, CD68 y CD154. Además, se pueden apreciar pequeñas inclusiones citoplasmáticas lineales y de aspecto estriado que reciben el nombre de gránulos de Birbeck, característicos de este tipo de patología. ${ }^{7}$ 
El tratamiento de esta enfermedad depende del grado de afectación, el GE monostótico es un proceso generalmente benigno con tendencia, en la mayoría de las ocasiones, a la remisión espontánea. Se han sugerido diversos planteamientos terpeúticos, como son una actitud expectante con observación de la evolución clínica, curetaje quirúrgico - resección completa, inyección de corticoides intralesionales y radioterapia, todos ellos dependiendo de la localización y la gravedad de la lesión. ${ }^{8}$

En líneas generales, los pacientes con GE tienen un pronóstico favorable, con una buena evolución tras aplicar el tratamiento más adecuado a la situación clínica, mientras que los presentan una afectación poliostótica y multisistémica tienen peor pronóstico y mayor tasa de recidiva.

\section{Consideraciones finales}

El granuloma eosinófilo es una afección poco común que afecta principalmente a la población infantil y adolescente, de carácter benigno, pero que precisa de un correcto diagnóstico para una intervención terapeútica temprana, descartando otro tipo de entidades malignas.

La historia clínica del paciente, así como la demostración de las imágenes radiológicas características, permiten llegar a un diagnóstico de presunción generalmente certero que en la mayoría de ocasiones se puede considerar definitivo.

Una estrategia de tratamiento y manejo individual y un enfoque quirúrgico selectivo deben considerarse como base para un resultado óptimo del paciente.

Limitaciones de responsabilidad

La responsabilidad del trabajo es sólo de los autores

Conflictos de interés

Ninguno

Fuentes de apoyo

No hubo fuentes de financiación ni apoyo.

\section{Originalidad del trabajo}

Este artículo es original y no ha sido enviado para su publicación a otro medio de difusión científica en forma completa ni parcialmente.

\section{Sesión de derechos}

Los participantes de este trabajo ceden el derecho de autor a la Universidad Nacional de Córdoba para publicar en la Revista de la Facultad de Ciencias Médicas y realizar las traducciones necesarias al idioma inglés.

\section{Participación de los autores}

Todos los autores hemos participado en la concepción del diseño, recolección de la información y elaboración del manuscrito, haciéndose públicamente responsables de su contenido y aprobando su versión final.

\section{Bibliografía}

1.Gómez-Ruiz, C., I. Buxadé-Martí, and G. Hinojosa-Bareas. "Granuloma eosinófilo óseo." SEMERGEN-Medicina de Familia 37.10 (2011): 573-575.

2. Fernandez $P$, Orejas G, Riaño I, Cobo A, Fernandez JM. Tumoración blanda en cráneo. An Esp Pediatr. (2001); 54:521-2.

3.Rojas CR, Garcia BC, Parra RD, Solar GA,Oyanedel QR, Diaz BF et al. Compromiso óseo en histiocitosis de células de Langerhans en el niño: estudio radiológico simple. Presentación clínica y diagnóstico radiológico. Rev Chil Radiol. (2005): 11:222-8.

4.Huang W, Yang X, Wu Z, Huang Q, Xiao J, Yang $M$ et al. Langerhans cell histiocytosis of spine: a comparative study of clinical imaging features, and diagnosis in children, adolescents and adults. Spine $\mathrm{J}$. (2013): 13:1108-17.

5.Gómez Ruiz C, Buxade-Marti I, Hinojosa Bareas G. Granuloma eosinófilo óseo. SEMERGEN. (2011): 37:573-5

6.Angelini A, Mavrogenis AF, Rimondi E, Rossi G, Ruggieri P. Current concepts for the diagnosis and management of eosinophilic granuloma of bone. J Orthop Traumatol. (2017): 18:83-90.

7.Bradford K, Rosenthal D, Mankin H. Langerhans cell histiocyotisis. Skeletal Radiol. (2007): 36:95-103.

8.Dong-Xiao N, Hui-tu N, An-zhou T,Ruo-ze C. Langerhans cell histiocytosis (histiocytosis X) of temporal bone. J Otol. (2007): 2:36-41. 